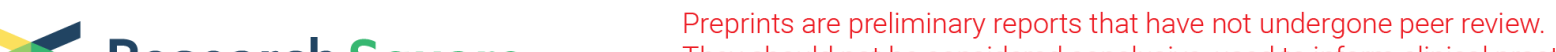 $\begin{array}{ll}\text { Research Square } & \text { They should not be considered conclusive, used to inform clinical practice, } \\ \text { or referenced by the media as validated information. }\end{array}$
}

\section{Liver tumor concurrent with chronic myelocytic leukemia and extreme thrombocytosis: A rare case report}

\section{Ping Han}

Tongji Hospital of Tongji Medical College of Huazhong University of Science and Technology

\section{Zhiqiang Han}

Tongji Hospital of Tongji Medical College of Huazhong University of Science and Technology

\section{Xia Mao}

Tongji Hospital of Tongji Medical College of Huazhong University of Science and Technology

Jin Wang

Tongji Hospital of Tongji Medical College of Huazhong University of Science and Technology

\section{Qinglu Li}

Tongji Hospital of Tongji Medical College of Huazhong University of Science and Technology

\section{Min Xiao}

Tongji Hospital of Tongji Medical College of Huazhong University of Science and Technology

\section{Li Meng}

Tongji Hospital of Tongji Medical College of Huazhong University of Science and Technology

Dean Tian

Tongji Hospital of Tongji Medical College of Huazhong University of Science and Technology

Zhenya Hong ( $\square$ hongzhenya@126.com )

\section{Case Report}

Keywords: Liver cancer, Chronic myelocytic leukemia, Thrombocytosis, Adenocarcinoma, Liver biopsy

Posted Date: March 17th, 2020

DOl: https://doi.org/10.21203/rs.3.rs-17513/v1

License: (c) (1) This work is licensed under a Creative Commons Attribution 4.0 International License.

Read Full License 


\section{Abstract}

Background Chronic myelocytic leukemia (CML) may occasionally occur after organ transplantation or long-term chemotherapy for solid tumors; Solid tumors secondary to long-term chemotherapy and biotherapy in CML have also been reported. However, the concurrence of solid tumor with $\mathrm{CML}$ and extreme thrombocytosis in an untreated patient is seldom reported.

Case presentation We describe a 61-year-old woman transferred to liver surgery department for the discovery of a large mass in the liver and an elevated plasmic AFP. She was initially diagnosed with liver cancer. Blood tests indicated a marked increase of platelets(2464x10 $9 / \mathrm{L})$. The chromosome examination of bone marrow biopsy indicated the existence of $t(9 ; 22)$ translocation, fluorescence in situ hybridisation (FISH) and PCR were both positive for the Bcr-Abl rearrangement. The diagnosis of CML was made. She received hydroxyurea and imatinib to treat $\mathrm{CML}$, and platelet-lowering therapy, and then underwent a liver biopsy, which suggestted a moderately-poorly differentiated adenocarcinoma, or might be a hepatic metastatic carcinoma. However, the patient refused further pathological examination and primary site screening for the tumor. She died six and a half months after discharge.

Conclusion: Here, we describe a rare case of liver cancer concurrent with $\mathrm{CML}$ and extreme thrombocytosis in an old patient. However, the exact relationship between the two tumors is still unclear, and more cases are desired.

\section{Background}

Chronic myeloid leukemia (CML) is a myeloproliferative disease caused by the reciprocal translocation of chromosome 9 and 22 which leads to a chimeric gene product known as Bcr-Abl[1]. Bcr-Abl fusion protein possesses constitutively activated Abl tyrosine kinase activity and activates downstream signalling pathways, including Ras/MAPK, JAK-STAT and PI3K/AKT, which are responsible for the pathogenesis of $\mathrm{CML}$ [2]. Clinically, CML is customarily considered a triphasic disease with an initial chronic phase (CP), an intermediate accelerated phase (AP) and a final, fatal blastic phase (BP)[3]. Patients with CML are usually characterised by extreme leucocytosis, myelocyte bulge, basophilia, eosinophilia in peripheral blood[4]. Some patients of CML can have mild to moderate thrombocytosis, there are even individual reports that platelets in CML patients can reach more than $10,000 \times 10^{9} / \mathrm{L}[5]$.

The relation between CML and solid tumors are rarely reported in four conditions: 1) Myeloid sarcoma (MS), commonly known as extramedullary acute myeloid leukemia (EM-AML), granulocytic sarcoma (GS) or chloroma, is a tumor composed of myeloid cells occurring at an extramedullary site[6]. The most common sites of involvement include small intestine, bone, skin, and lymphnode[7]. It can occur in different clinical settings: in patients with acute myeloid leukemia (AML) as a localized tissue mass, as blast crisis in patients with chronic myeloid leukemia (CML) or leukemic transformation in myelodysplastic syndrome (MDS), before AML and as an isolated neoplasm without evidence of AML[8]; 2) Secondary solid tumors after treatment for $C M L$, the solid tumors reported after $C M L$ treatment 
including hepatocellular carcinoma(HCC)[9], pulmonary carcinoid[10], and thyroid adenocarcinoma[11]. The underling mechanisms is unclear, but may be relevant to the chemotherapy induced DNA damage, multiple genetic alterations and increasing host susceptibility to oncogenic viruses due to immunosuppression[9]; 3) Secondary CML after treatment for solid tumors, the formation of CML after treatment for solid tumors have been reported in non-small cell lung cancer[12], thyroid carcinoma[13, 14], breast cancer[15], and gastric adenocarcinoma[16, 17]. Up to now, evidence is lacking as to the frequency of therapy-related CML complicating cytotoxic therapy. 4) CML after organ transplant, more than 30 cases of CML associated with organ transplants have been reported up to now, most of them developed after kidney transplants $[18,19]$. The development of $C M L$ in this situation may be associated with the postorgan transplant immunosuppressed state. However, it remains controversial whether the incidence of $\mathrm{CML}$ in such patients is truly higher than the general population owing to the limited number of reported cases.

In this case report, we reported the concurrent of liver cancer with CML and extreme thrombocytosis in an untreated old woman.

\section{Case Presentation}

A 61-year-old woman was transferred to our hospital with complaints of upper abdominal pain accompanied by anorexia for four months. Doctors in local hospital found a large mass in her right hepatic lobe by magnetic resonance imaging (MRI) and an elevated plasma level of AFP to $216.5 \mathrm{ng} / \mathrm{ml}$, and she was initially diagnosed with liver cancer and admitted to our liver surgery department. She had a 5-year history of hepatitis B, but has never been treated; she also had a 5-year history of hypertension, and treated with indapamide tablet.

The physical examination on admission showed no jaundice, ascites, pedal edema or spider naevi, the liver and spleen are not touched below the costal margin. There were no obvious enlargement of superficial lymph nodes, and the remaining physical examination findings were unremarkable. Laboratory tests at admission (Table 1) showed a hemoglobin level of $111 \mathrm{~g} / \mathrm{L}$, white blood cell count of $7.01 \times$ $10^{9} / \mathrm{L}$, and platelet count of $2464 \times 10^{9} / \mathrm{L}$. The liver function test results were serum alanine aminotransferase of $55 \mathrm{U} / \mathrm{L}$, serum aspartate aminotransferase of $82 \mathrm{U} / \mathrm{L}$, and globulin of $69 \mathrm{~g} / \mathrm{L}$. HBVDNA was $2.11 \times 10^{7} \mathrm{IU} / \mathrm{ml}$. AFP was $308.8 \mathrm{ng} / \mathrm{ml}$. Abdominal color Doppler ultrasonography showed a large hypoechoic area of about $9.5 \mathrm{~cm} \times 5.7 \mathrm{~cm}$ in the right lobe of the liver, which was irregular in shape, unclear in boundary and uneven in internal echo, and the distal part of the right hepatic vein was not clearly displayed due to the compression of the mass(Fig. 1A). Abdominal contrast-enhanced CT showed a slightly low-density lesion in the right lobe of the liver with a maximum diameter of about $9.1 \times 5.5 \mathrm{~cm}$, and was slightly uneven enhancement and delayed enhancement(Fig. 1B,C). Hilar and retroperitoneal lymph nodes were increased and enlarged. These imaging and biochemical examination results suggested a neoplastic lesion in the liver, particularly HCC. 
Table 1

The main laboratory test results at admission

\begin{tabular}{|lll|}
\hline & Our values & Normal range \\
\hline WBC & $7.01 \times 10^{9} / \mathrm{L}$ & $3.50-9.50 \times 10^{9} / \mathrm{L}$ \\
\hline Neutrophils & $3.28 \times 10^{9} / \mathrm{L}$ & $1.80-6.30 \times 10^{9} / \mathrm{L}$ \\
\hline RBC & $3.71 \times 10^{12} / \mathrm{L}$ & $3.80-5.10 \times 10^{12} / \mathrm{L}$ \\
\hline Hb & $111 \mathrm{~g} / \mathrm{L}$ & $115-150 \mathrm{~g} / \mathrm{L}$ \\
\hline AST & $2464 \times 10^{9} / \mathrm{L}$ & $125-350 \times 10^{9} / \mathrm{L}$ \\
\hline ALT & $82 \mathrm{U} / \mathrm{L}$ & $0-32 \mathrm{U} / \mathrm{L}$ \\
\hline Total bilirubin(TBil) & $8.9 \mathrm{umol} / \mathrm{L}$ & $3.4-20.5 \mathrm{umol} / \mathrm{L}$ \\
\hline LDH & $387 \mathrm{U} / \mathrm{L}$ & $135-214 \mathrm{U} / \mathrm{L}$ \\
\hline Total protein & $92.4 \mathrm{~g} / \mathrm{L}$ & $64-83 \mathrm{~g} / \mathrm{L}$ \\
\hline globulin & $64.4 \mathrm{~g} / \mathrm{L}$ & $20-35 \mathrm{~g} / \mathrm{L}$ \\
\hline Creatinine & $67 \mu \mathrm{mol} / \mathrm{L}$ & $45-84 \mu \mathrm{mol} / \mathrm{L}$ \\
\hline AFP & $308.8 \mathrm{ng} / \mathrm{ml}$ & $0-7 \mathrm{ng} / \mathrm{ml}$ \\
\hline CEA & $4.69 \mathrm{ng} / \mathrm{mL}$ & $0-5 \mathrm{ng} / \mathrm{mL}$ \\
\hline CA19-9 & $0.6 \mathrm{U} / \mathrm{mL}$ & $0-34 \mathrm{U} / \mathrm{mL}$ \\
\hline ESR & $95 \mathrm{~mm} / \mathrm{H}$ & $0-22 \mathrm{~mm} / \mathrm{H}$ \\
\hline ANA & $1: 320$ & - \\
\hline Urine protein & ++ & - \\
\hline HBV-DNA & $2.11 \times 10^{7} \mathrm{IU} / \mathrm{ml}$ & - \\
\hline PT & $17.3 \mathrm{~s}$ & $11.5-14.5$ \\
\hline APTT & $46.8 \mathrm{~s}$ & $29-42 \mathrm{~s}$ \\
\hline
\end{tabular}

This patient was transferred to our hematology department, further biochemical examination resluts showed that ESR was $95 \mathrm{~mm} / \mathrm{H}$, beta-2 microglobulin was $4.62 \mathrm{mg} / \mathrm{L}$ and anti-nuclear antibody was 1:320. No M protein was found in the test of monoclonal gamma globulin disease. A bone marrow aspiration and biopsy was performed to examine bone marrow, and results showed a hypercellular marrow with marked granulocytic and megakaryocytic hyperplasia(Fig. 2A,B). FISH analysis with Bcr/Abl DF probe was used to detect Bcr/Abl loci, when counting 200 cells in interphase, about $20 \%$ of the cells 
expressed two fusion signals, one red signal and one green signal(Fig. 3A), suggesting that Bcr/Abl fusion was positive. Chromosome examination also indicated the existence of $t(9 ; 22)$ translocation(Fig. 3B). Quantitative PCR for Bcr/Abl (p210) fusion transcript showed that the copy number of Bcr/Abl transcript was 421662, the ABL transcript copy was 384566, the ratio of Bcr/Abl to Abl transcript was $109.65 \%$, and the international standardisation (IS) value was $109.65 \%$. The diagnosis of chronic-phase CML was made. She received hydroxyurea $(1 \mathrm{~g}$ po tid) and imatinib $(0.4 \mathrm{~g} \mathrm{po} \mathrm{qd})$ to treat $\mathrm{CML}$, and platelet-lowering therapy with anagrelide( $0.5 \mathrm{mg}$ po bid), bayaspirin(100 $\mathrm{mg}$ po qd) and sodium bicarbonate $(1 \mathrm{~g}$ po tid). She also received anti-hepatitis B virus therapy with entecavir ( $0.5 \mathrm{mg}$ po qd). She developed agranulocytosis on the 7th day of treatment with hydroxyurea(Fig. 4A), so we reduced the dosage of hydroxyurea and gradually stopped it. She was treated with anti-infection and recombinant human granulocyte stimulating factor injection. Her hemoglobin and platelets gradually decreased(Fig. 4B,C). On the 14th day of hydroxyurea treatment, platelets returned to normal range (317 $\times 10^{9} / \mathrm{L}$ ), three days later, it continued to drop to $21 \times 10^{9} / \mathrm{L}$, but gradually returned to normal. The main therapeutic drugs during this course are shown in Fig. 4D. The second bone marrow aspiration and biopsy results both suggested the erythrocyte and granulocyte series of bone marrow were suppressed, quantitative PCR for Bcr/Abl showed that the copy number of Bcr/Abl transcript was 79692, the Abl transcript copy was 1282604 , the ratio of $\mathrm{Bcr} / \mathrm{Abl}$ to $\mathrm{Abl}$ transcript was $6.21 \%$, and the international standardisation (IS) value was $2.36 \%$. Flow cytology of bone marrow suggested increased proportion of lymphocyte, no abnormal expression of T lymphocytes, NK cells and monoclonal B lymphocytes. The proportion of myeloid primordial cells was significantly decreased, and the neutrophils and monocytes were mainly in the mature stage(complete results is available in Additional file1)

She underwent a liver biopsy when her blood routine results returned to near normal, HE staining suggested heterotypic adenoid and solid cell nests with necrosis in the chronic inflammatory liver tissue(Fig. 5A). The Ki-67 index was about 30-40\%(Fig. 5B). Immunohistochemical studies showed positive staining of VILLIN,CK7, and EMA, while negative for Hepatocyte, Glypican-3, Arginasc1, AFP, CK19, CK20, CDX2, TTF-1, NapsinA, PAX8, ER, PR, and GATA3(Fig. 5C-R). Pathologists concluded a moderately-poorly differentiated adenocarcinoma, and hepatic metastatic carcinoma can't be excluded. However, the patient refused further pathological examination and primary site screening for tumor, and asked to be discharged from hospital. She continued to take imatinib after discharge with a dosage of $0.4 \mathrm{~g}$ per day. However, she took the drug by herself at a reduced dose of $0.1 \mathrm{~g}$ per day due to a severe gastrointestinal reaction. At the fourth month of discharge, her platelet count was in normal range $(272 \times$ $\left.10^{9} / \mathrm{L}\right)$, while a color Doppler ultrasonography showed that the liver tumor was enlarged $(9.8 \mathrm{~cm}$ $x 7.3 \mathrm{~cm}$ ). She died six and a half months after discharge, and the exact cause of her death was not clear.

\section{Discussion And Conclusions}

$\mathrm{CML}$ is a clonal disorder of hematopoietic stem cell characterised by the presence of Philadelphia chromosome $\mathrm{t}(9: 22)$, it is manifested with increased number of myeloid cell count, and marked leucocytosis, myelocyte bulge, basophilia, eosinophilia and normal to mild thrombocytosis in peripheral 
blood[4]. Rare cases of CML may present with an isolated, marked thrombocytosis, defined as a platelet count more than $1000 \times 10^{9} / \mathrm{L}[20]$. Sora et al evaluated the marked thrombocytosis of $\mathrm{CML}$ in a large series of patients from 16 different Italian haematological centres from January 2002 to December 2015[21], and 87 of $1591 \mathrm{CML}$ patients with extreme thrombocytosis were identified, with platelet count ranging from $1054 \times 10^{9} / \mathrm{L}$ to $4720 \times 10^{9} / \mathrm{L}$. CML patients with atypical clinical features and severe thrombocytosis were often mimicked with essential thrombocytosis (ET) as reported previously[22]. In our case, the patient's platelet count was as high as $3622 \times 10^{9} / \mathrm{L}$, but her erythrocyte and granulocyte series in peripheral blood were generally normal. However, FISH, chromosome examination and RT-PCR confirmed the diagnosis of CML. Moreover, bone marrow aspiration and biopsy revealed megakaryocytes that were smaller than normal cells and had a typical hyperlobated round nuclei in morphology. Therefore, we and other researchers propose that every case of ET should be tested for the Philadelphia chromosome to avoid missed diagnosis of $\mathrm{CML}[23]$.

The main pathogenesis of CML is the reciprocal translocation between chromosomes 9 and 22, which leads to the tyrosine kinase coding gene $\mathrm{ABL}$ of chromosome 9 translocated into BCR region of chromosome 22. An important result of this chromosome translocation is the product of fusion gene AblBcr that encodes a deregulated tyrosine kinase resulting in manifestations of CML. Inhibition of Bcr-Abl oncogene expression and protein function are the primary treatment of CML based on its pathogenesis[24]. Bcr-Abl tyrosine-kinase inhibitors (TKI) are the first-line therapy for CML, among them, imatinib is one of the most classic, first-line drug[25]. In the recent study of Sora et al as mentioned previously, the majority of patients patients received a pre-treatment with hydroxycarbamide, and then treated with TKIs(63 patients received imatinib, 16 received dasatinib, and 8 were given nilotinib), 87\% patients obtained a complete cytogenetic response (CCyR) or a major molecular response (MMR) after 12 months of treatment[21]. In our case, the patient received a pre-treatment with hydroxycarbamide and platelet-lowering therapy with anagrelide, but it did not achieve a relevant reduction in platelet count. However, when imatinib therapy was started, the platelet count rapidly decreased to the normal range. At the four-month follow-up after discharge, her platelet count remained in normal range.

Another issue in our report is the solid tumor complicating with $\mathrm{CML}$ in one patient. The abnormal elevated AFP, liver masses in CT imaging, and past history of hepatitis B infection all support the clinical diagnosis of liver tumor, particularly HCC. However, continuous monitoring of tumor markers revealed a downward trend in AFP(FigureS1). The pathological diagnosis of liver biopsy suggestted a moderatelypoorly differentiated adenocarcinoma, and it may also be metastatic liver tumor. However, neither abdominal enhanced CT, chest CT nor gastroscopy(FigureS2) showed tumors in other parts of the abdomen. In view of the particularity of liver tumors concurrent with hematological tumors, we consulted the literature and found some reports about liver tumors coexisted with hematological tumors. Katoh reported a 55-year-old Japanese man with CML, who had received an alkylating agent for 16 years, was diagnosed as HCC with clinically evident splenic metastases[9]. This is the first report in the literature on $\mathrm{HCC}$ in association with CML. The authors analyzed the long-term chemotherapy induced DNA damage may have endowed the HCC with an aggressive proliferative potential[9]. Ansari presented a case of a 72- 
year-old man with a diagnosis of CML, showing subsequently with a liver mass which was pathological diagnosed as Histiocytic sarcoma (HS)[26]. The liver mass showed a retained BCR-ABL1 translocation suggesting clonality between the CML and HS. Therefore, the author proposed that the concurrent expression of immunoglobulin heavy (IGH)-/light-chain rearrangements or cytogenetic markers common to the primary CML suggested an evolutionary mechanism involving lineage switching that could potentially be affected by genetic or epigenetic factors which may occur at the level of a progenitor or the malignant cell itself[26]. MS is a rare extramedullary presentation of neoplastic myeloid cells. They may occur before, concurrent with, or after the diagnosis of myeloproliferative disorders, such as AML or $\mathrm{CML}[27,28]$. Norsworthy reviewed 51 cases of biopsy-proven MS involving the liver, biliary tree or pancreas[29], most cases presented with systemic disease, mainly in association with AML and CML. The main symptom includes jaundice, right upperquadrant abdominal pain, fatigue, anorexia, nausea and vomiting. Many cases were initially diagnosed as cholecystitis, pancreatitis or carcinoma, especially in those with unknown hematological diseases, and underwent surgery. As immunohistochemistry confirmed, the most commonly expressed cell surface markers of MS in these cases were myeloperoxidase (63\%), CD68 (40\%), CD45 (30\%), CD34 (30\%), CD43 (30\%), CD117 (28\%), CD33 (15\%), lysozyme (15\%) and CD13(8\%)[29]. Unfortunately, for our case, there are no additional samples for further immunohistochemical detection of MS markers. Although the platelet count was reduced to a normal range, imatinib therapy did not reduce the size of the liver tumor.

In summary, we presented a rare case of liver cancer concurrent with CML and extreme thrombocytosis in an old patient. Although the exact pathological relationship between the liver cancer and CML in this case is unknown, we wish there are more reports on the concurrent $\mathrm{CML}$ and solid tumors like our case to explore the underline mechanisms.

\section{Declarations}

Abbreviations: PCR: polymerase chain reaction; CT: computed tomography; ESR: erythrocyte sedimentation rate; NK cell: natural killer cell; AFP: alpha-fetoprotein

Author Contributions: Ping Han and Zhiqiang Han collected and analyzed the data, and wrote the first draft of the manuscript; Xia Mao, Jin Wang, Min Xiao and Qinglu Li performed the tests of bone marrow cytology, chromosome, FISH and flow cytometry. Li Meng and Dean Tian were in charge of the patient's management; Zhenya Hong supervised patient's management, critically revised the text, and made substantial scientific contributions. All authors approved the final version of the manuscript.

Acknowledgements: The authors would like to thank all members of the study team, the patient and their family.

Funding: This paper is supported by grants from the National Science Foundation of China (No. 81702396, 81772788, and 81873430). 
Availability of data and materials: The datasets supporting the conclusions of this article are included within the article and Additional file 1-3.

Ethics approval and consent to participate: The study was conducted in accordance with the Declaration of Helsinki, and the protocol was approved by the Ethics Committee of Tongji Hospital, Tongji Medical College, Huazhong University of Science and Technology. The patient' daughter gave her written informed consent in accordance with the Declaration of Helsinki.

Consent for publication: The authors have obtained consent to publish from the participants to report individual patient data

Competing interests: We have no conflicts of interest to declare.

\section{References}

1.

Lugo TG, Pendergast AM, Muller AJ, Witte ON. Tyrosine kinase activity and transformation potency of bcrabl oncogene products. Science. 1990;247:1079-82.

2 .

Melo JV, Deininger MW. Biology of chronic myelogenous leukemia-signaling pathways of initiation and transformation. Hematol Oncol Clin North Am. 2004;18:545-68. vii-viii.

3.

Chiba A, Toya T, Mizuno H, Tokushige J, Nakamura F, Nakazaki K, et al. Chronic myelogenous leukemia presenting with central nervous system infiltration, successfully treated with central nervous systemdirected chemotherapy followed by allogeneic stem cell transplantation. Int J Hematol. 2018;108:640-6. 4.

Soverini S, Mancini M, Bavaro L, Cavo M, Martinelli G. Chronic myeloid leukemia: the paradigm of targeting oncogenic tyrosine kinase signaling and counteracting resistance for successful cancer therapy. Mol Cancer. 2018;17:49.

5 .

McCarthy LJ, Graves VL, Eigen H, McGuire WA. Platelet apheresis for extreme thrombocytosis in an 11year-old girl with CML. Transfus Med. 1991;1:187-9.

6.

Avni B, Koren-Michowitz M. Myeloid sarcoma: current approach and therapeutic options. Ther Adv Hematol. 2011;2:309-16.

7.

Breccia M, Mandelli F, Petti MC, D'Andrea M, Pescarmona E, Pileri SA, et al. Clinico-pathological characteristics of myeloid sarcoma at diagnosis and during follow-up: report of 12 cases from a single institution. Leuk Res. 2004;28:1165-9.

8. 
Siraj F, Kaur M, Dalal V, Khanna A, Khan AA. Myeloid sarcoma: a report of four cases at unusual sites. Ger Med Sci. 2017;15:Doc03.

9.

Katoh M, Takeuchi K, Murashima N, Nakajima M, Yamaguchi H, Endo Y, et al. Hepatocellular carcinoma with splenic metastasis developing after 16 years of chemotherapy for chronic myelogenous leukemia: a case report. Jpn J Clin Oncol. 1994;24:111-5.

10.

Fiebiger W, Kurtaran A, Novotny C, Kainberger F, Dekan G, Raderer M. Occurrence of a pulmonary carcinoid following allogeneic stem cell transplantation for chronic myelogenous leukemia: a case report. Ann Hematol. 2003;82:374-6.

11.

Morrison AE, O'Grady J, Parker AC, McLaren K. Metastatic papillary carcinoma of thyroid in a patient undergoing allogeneic BMT for CML. Br J Haematol. 1994;86:873-5.

12.

Waller CF, Fetscher S, Lange W. Secondary chronic myelogenous leukemia after chemotherapy followed by adjuvant radiotherapy for small cell lung cancer. Leuk Res. 1999;23:961-4.

13.

Wang KL, Lin LY, Chen PM, Lin HD. Chronic myeloid leukemia after treatment with 131 for thyroid carcinoma. J Chin Med Assoc. 2005;68:230-3.

14.

Pavithran K, Doval DC. Chronic myeloid leukemia in a man with papillary carcinoma of the thyroid treated with radioactive iodine. Am J Clin Oncol. 2005;28:216.

15.

Bauduer F, Ducout L, Dastugue N, Marolleau JP. Chronic myeloid leukemia as a secondary neoplasm after anti-cancer radiotherapy: a report of three cases and a brief review of the literature. Leuk Lymphoma. 2002;43:1057-60.

16.

Uemura Y, Imai T, Machida T, Shima Y. [Secondary chronic myelogenous leukemia following postoperative TS-1 therapy for advanced gastric cancer]. Rinsho Ketsueki. 2010;51:559-63.

17.

Tsuzuki M, Handa K, Yamamoto K, Hasegawa A, Yamamoto Y, Watanabe M, et al. Chronic myeloid leukemia following chemotherapy with 5'-deoxy-5-fluorouridine for gastric cancer. Intern Med. 2008;47:1739-41.

18.

Eishei Oskuei A, Makhdoomi K, Abkhiz S, Vossoghian S, Farrokhpour M. Successful treatment of Chronic Myelogenic Leukemia (CML) with imatinib after renal transplantation. Arch Iran Med. 2014;17:388-90. 19.

le Coutre P, Schwarz M, Daniel P, Dorken B. Post-transplantation chronic myeloid leukemia. Clin Adv Hematol Oncol. 2011;9:627-9.

20. 
Turakhia SK, Murugesan G, Cotta CV, Theil KS, Thrombocytosis. and STAT5 activation in chronic myelogenous leukaemia are not associated with JAK2 V617F or calreticulin mutations. J Clin Pathol. 2016;69:713-9.

21.

Sora F, lurlo A, Sica S, Latagliata R, Annunziata M, Galimberti S, et al. Chronic myeloid leukaemia with extreme thrombocytosis at presentation: incidence, clinical findings and outcome. $\mathrm{Br} \mathrm{J}$ Haematol. 2018;181:267-70.

22.

Tefferi A. Ultra high platelet count might be a characteristic feature of chronic myeloid leukemia rather than essential thrombocythemia. Leuk Res. 2007;31:416-7.

23.

Ebrahem R, Ahmed B, Kadhem S, Truong Q. Chronic Myeloid Leukemia: A Case of Extreme Thrombocytosis Causing Syncope and Myocardial Infarction. Cureus. 2016;8:e476.

24.

Massaro F, Colafigli G, Molica M, Breccia M. Novel tyrosine-kinase inhibitors for the treatment of chronic myeloid leukemia: safety and efficacy. Expert Rev Hematol. 2018;11:301-6.

25.

Rosti G, Castagnetti F, Gugliotta G, Baccarani M. Tyrosine kinase inhibitors in chronic myeloid leukaemia: which, when, for whom? Nat Rev Clin Oncol. 2017;14:141-54.

26.

Ansari J, Naqash AR, Munker R, El-Osta H, Master S, Cotelingam JD, et al. Histiocytic sarcoma as a secondary malignancy: pathobiology, diagnosis, and treatment. Eur J Haematol. 2016;97:9-16.

27.

Neiman RS, Barcos M, Berard C, Bonner H, Mann R, Rydell RE, et al. Granulocytic sarcoma: a clinicopathologic study of 61 biopsied cases. Cancer. 1981;48:1426-37. 28.

Piccaluga PP, Ascani S, Agostinelli C, Paolini S, Laterza C, Papayannidis C, et al. Myeloid sarcoma of liver: an unusual cause of jaundice. Report of three cases and review of literature. Histopathology. 2007;50:802-5.

29.

Norsworthy KJ, Bhatnagar B, Singh ZN, Gojo I. Myeloid Sarcoma of the Hepatobiliary System: A Case Series and Review of the Literature. Acta Haematol. 2016;135:241-51.

\section{Figures}




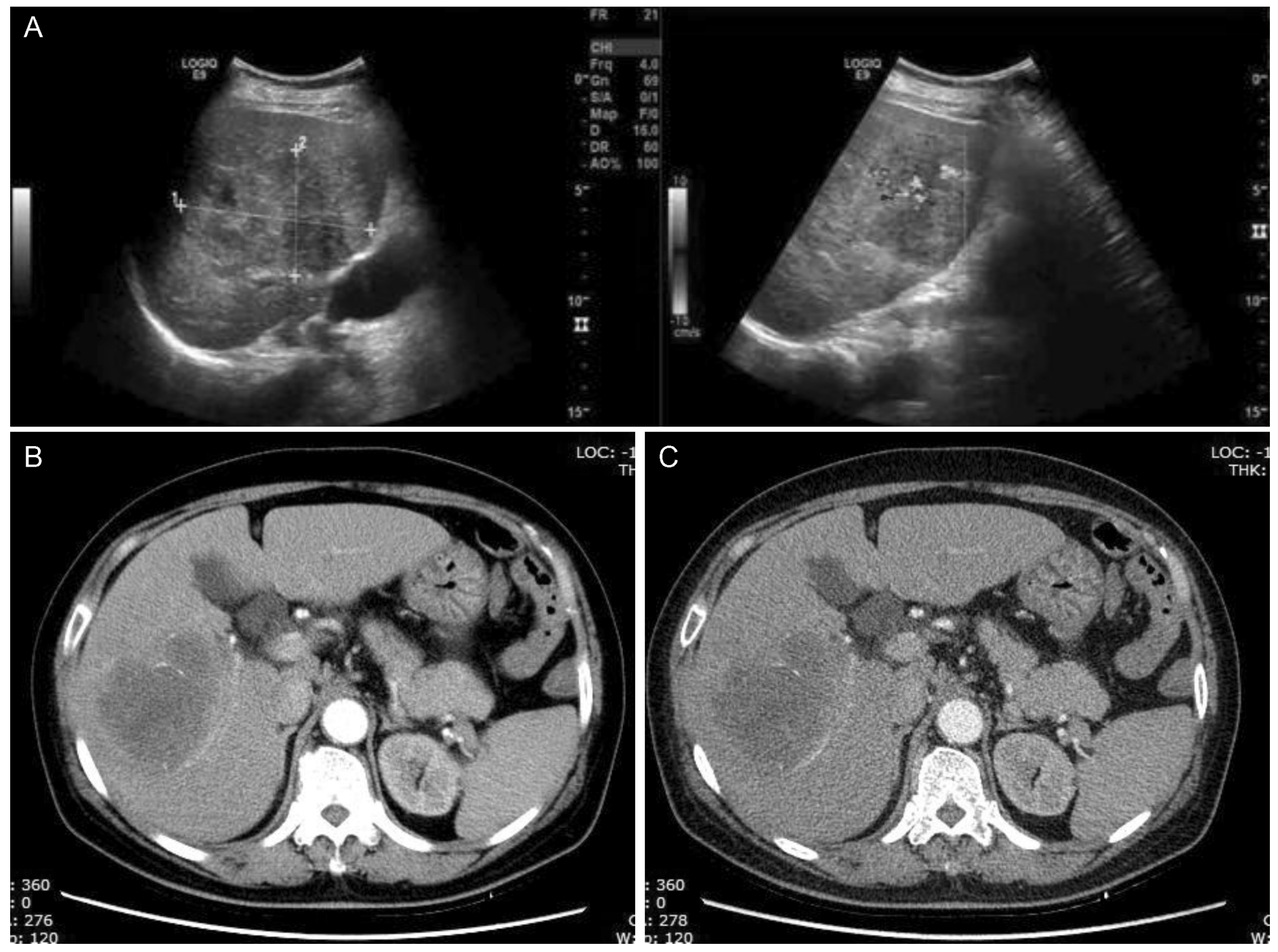

\section{Figure 1}

Imaging features of the liver tumor in the patient. Abdominal color Doppler ultrasonography(A) showed a large hypoechoic area in the right lobe of the liver. It was irregular in shape, unclear in boundary and uneven in internal echo, and the distal part of the right hepatic vein was compressed; abdominal contrastenhanced CT(B) showed a $9.1 \times 5.5 \mathrm{~cm}$ slightly low-density lesion in the right lobe of the liver, it was slightly uneven enhancement and delayed enhancement. 

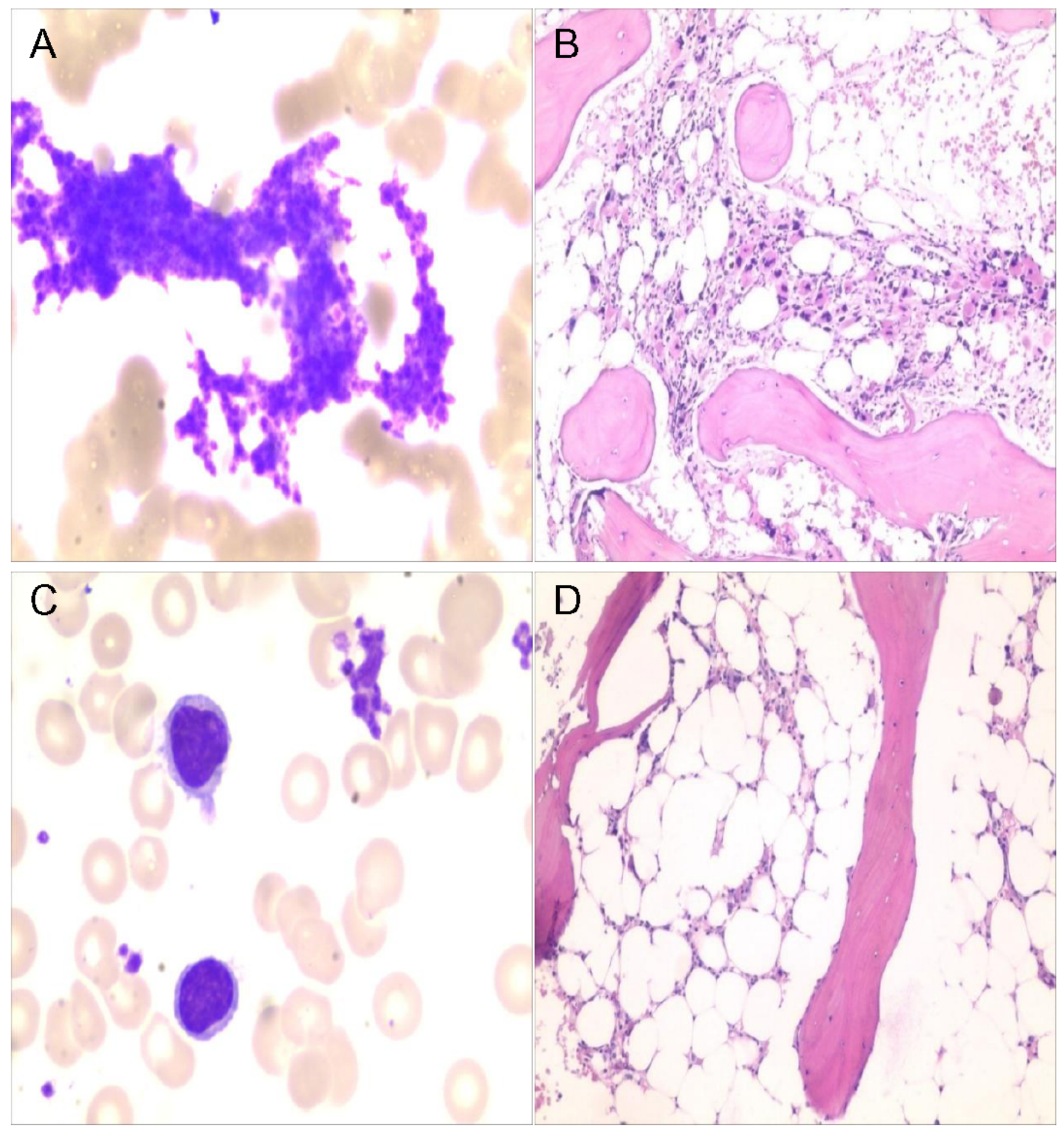

\section{Figure 2}

Bone marrow aspiration and biopsy during hospitalization. The cytology of bone marrow at admission(A) showed a large number of platelet aggregation on bone marrow cytology slide. Megakaryocytes can be easily found, and there were 16 granular megakaryocyte and 4 thromocytogenic megakaryocyte in 20 megakaryocytes. excessive nuclear lobulation, abnormal nuclear lobulations were also displayed. The bone marrow biopsy at admission(B) suggested the megakaryocytes were clustered or scattered in 
different cell sizes, with hypolobation (mononuclear) or multinucleation (two or more round separated nuclei). The second bone marrow cytology(C) and biopsy (D) after treatment both showed that the proliferation of bone marrow was severely inhibited, megakaryocytes were easily seen and hypolobations of megakaryocytes were also observed.

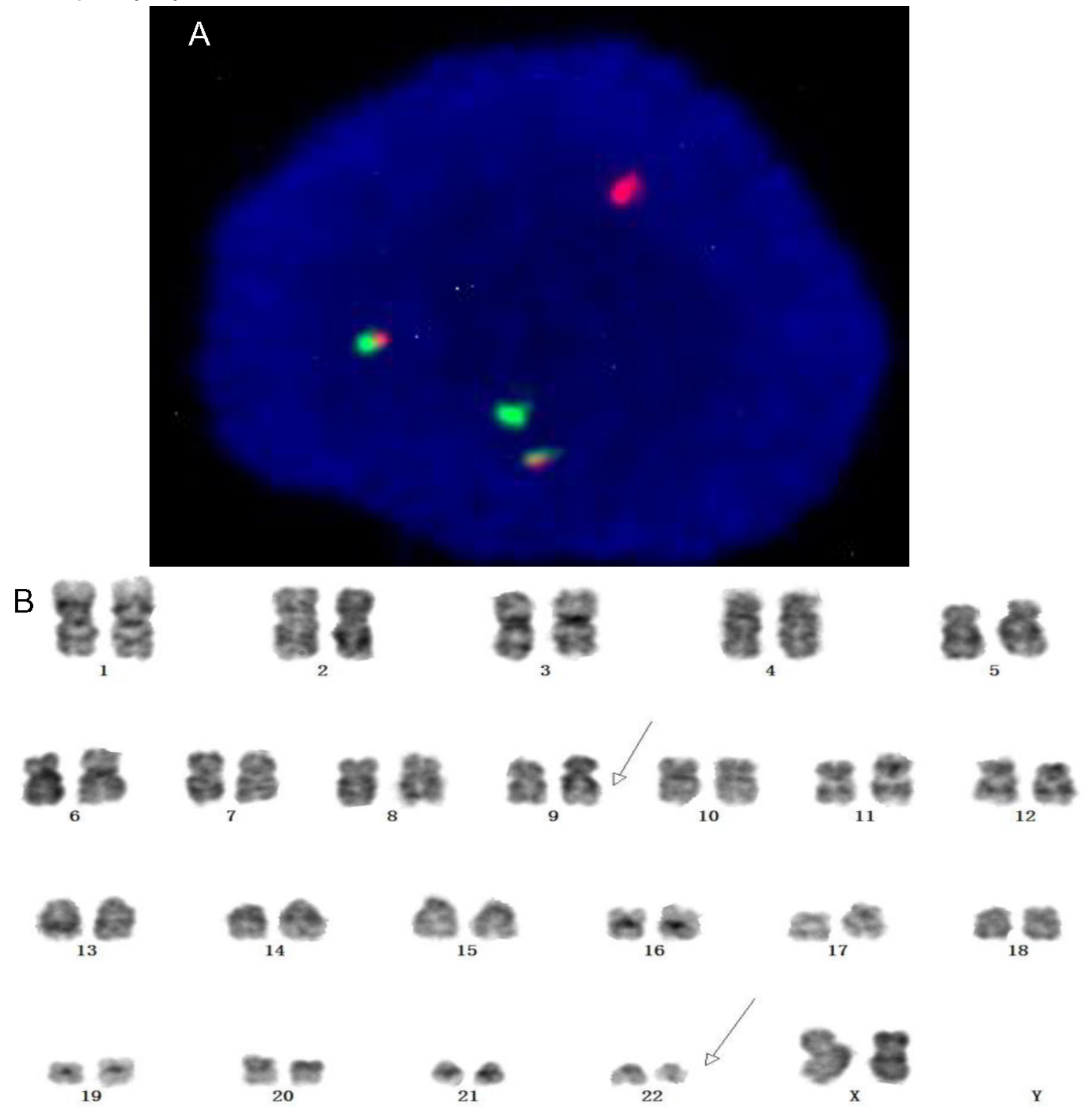

\section{Figure 3}

Bone marrow genetic testing results. A representative image of $\mathrm{FISH}$ analysis with $\mathrm{Bcr} / \mathrm{Abl} \mathrm{DF}$ probe(A). The red probe represents $\mathrm{Abl}$ (chromosome 9), the green probe Bcr (chromosome 22), and the yellow area shows where the two fluorophores are in close contact, indicating the gene fusion. Chromosome 
examination (B) indicated the reciprocal translocation of long arm of chromosome 22 and the long arm of chromosome 9 , arrows indicated the chromosome translocation regions.

A

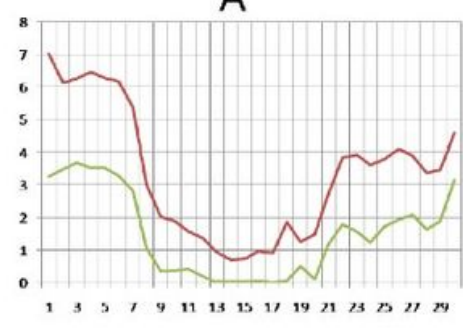

B

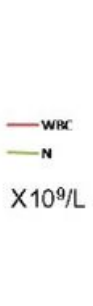

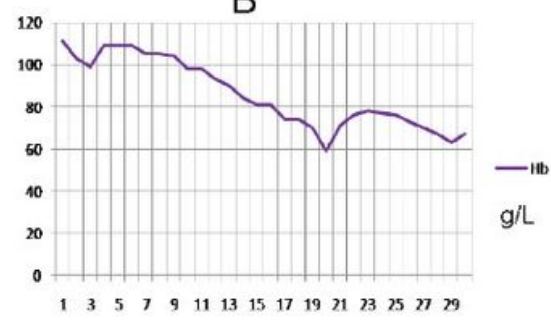

C

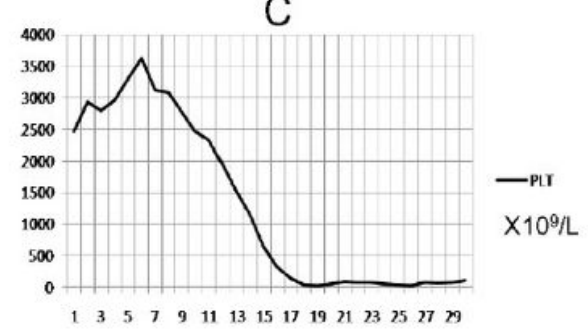

D

\begin{tabular}{|c|c|c|c|c|c|c|c|c|c|c|c|c|c|c|c|}
\hline & \multicolumn{14}{|c|}{ Days after admission } & \multirow[b]{2}{*}{15} \\
\hline & 1 & 2 & 3 & 4 & 5 & 6 & 7 & 8 & 9 & 10 & 11 & 12 & 13 & 14 & \\
\hline Hydroxyurea & & $4 \mathrm{~g}$ & $4 g$ & $4 \mathrm{~g}$ & $4 \mathrm{~g}$ & $4 \mathrm{~g}$ & $4 \mathrm{~g}$ & $4 \mathrm{~g}$ & $4 g$ & $2 \mathrm{~g}$ & $15 \mathrm{~g}$ & & & & \\
\hline Asprin & & $100 \mathrm{mg}$ & $100 \mathrm{mg}$ & $100 \mathrm{mg}$ & $100 \mathrm{mg}$ & $100 \mathrm{mg}$ & $100 \mathrm{mg}$ & $100 \mathrm{mg}$ & $100 \mathrm{mg}$ & $100 \mathrm{mg}$ & $100 \mathrm{mg}$ & $100 \mathrm{mg}$ & $100 \mathrm{mg}$ & $100 \mathrm{mg}$ & $100 \mathrm{mg}$ \\
\hline Anagrelide & & & & & & & & $1 \mathrm{mg}$ & $1 \mathrm{mg}$ & $1 \mathrm{mg}$ & $1 \mathrm{mg}$ & $1 \mathrm{mg}$ & $1 \mathrm{mg}$ & $1 \mathrm{mg}$ & ling \\
\hline Imatinib & & & & & & & & $400 \mathrm{mg}$ & $400 \mathrm{mg}$ & $400 \mathrm{mg}$ & $400 \mathrm{mg}$ & $400 \mathrm{mg}$ & $400 \mathrm{mg}$ & & \\
\hline \multirow[t]{3}{*}{ ThG-CSF } & & & & & & & & & & & $100 u g$ & $200 u g$ & $300 u g$ & $300 u g$ & \\
\hline & \multicolumn{14}{|c|}{ Days after admission } & \\
\hline & 16 & 17 & 18 & 19 & 20 & 21 & 22 & 23 & 24 & 25 & 26 & 27 & 28 & & \\
\hline thG-CSF & $300 u g$ & 300ug & 300ug & $300 u g$ & & & & & & & & & & & \\
\hline rHuGM-CSF & 300ug & 300ug & 300ug & 300ug & & & & & & & & & & & \\
\hline ThIL-11 & & & $15 \mathrm{mg}$ & & & & & & & & & & & & \\
\hline $\begin{array}{l}\text { Blood } \\
\text { transfusion }\end{array}$ & & & $\begin{array}{l}\text { platelet } \\
\text { plasma } \\
\text { CRCs }\end{array}$ & & & & & & platelet & & & & & & \\
\hline
\end{tabular}

\section{Figure 4}

Treatments and the response to treatments of the patient. A,B,C representing the trend of white blood cells, hemoglobin and platelets after admission respectively. The abscissa represents the days after admission, and the ordinate shows the value of $\operatorname{WBC}(x 109 / \mathrm{L})$, hemoglobin $(\mathrm{g} / \mathrm{L})$ and platelets $(\mathrm{x} 109 / \mathrm{L})$, respectively. $\mathrm{D}$ showing the main drugs and treatments during hospitalization. rhG-CSF, recombinant human granulocyte-colony stimulating factor. rHuGM-CSF, recombinant human granulocyte-macrophage colony-stimulating factor. rhIL-11, recombinant human interleukin 11. CRCs, red blood cells suspension. 


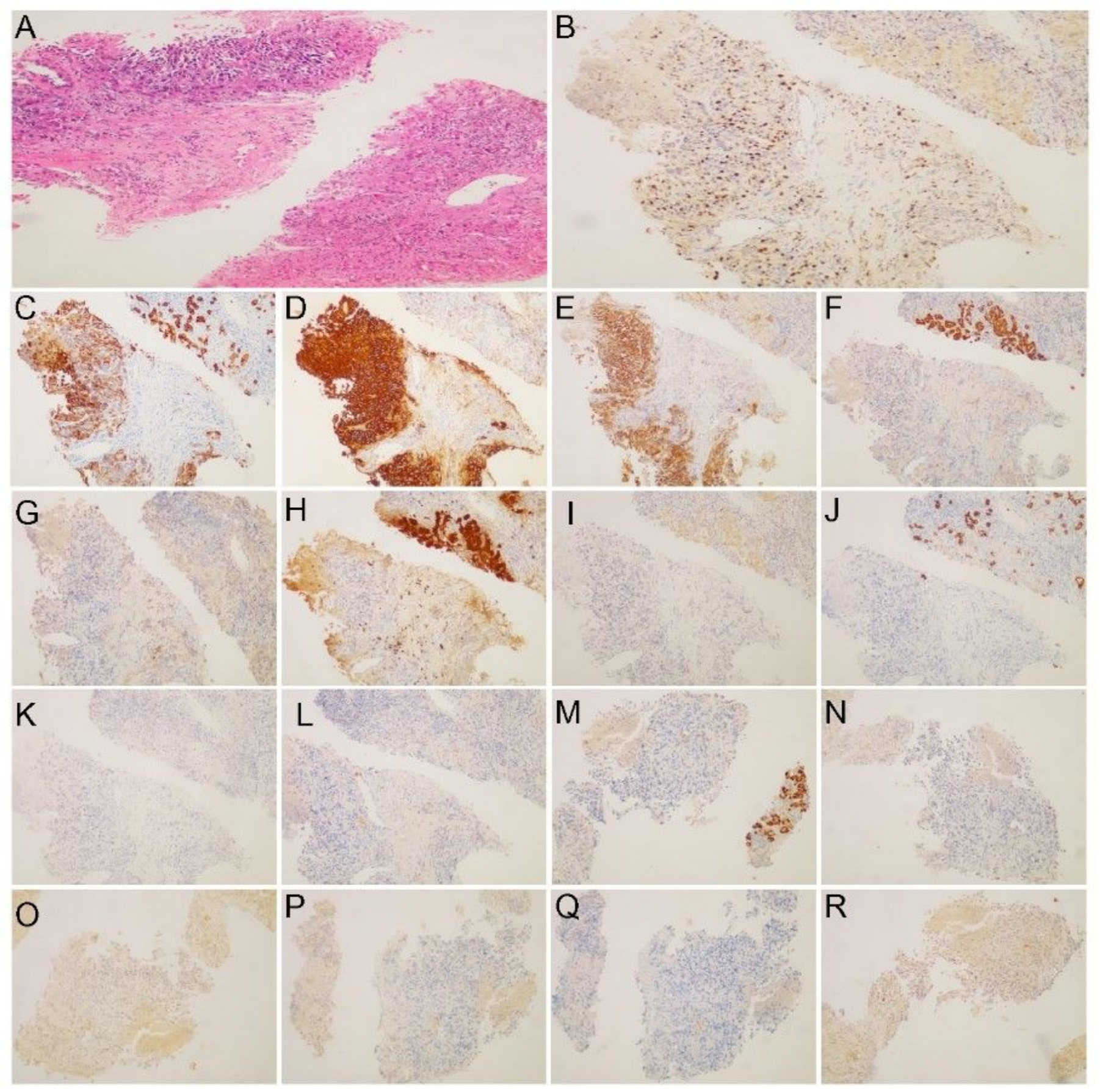

Figure 5

HE and immunohistochemical stainings of puncture liver tissues. HE staining of liver biopsy specimen(A) showed heterotypic adenoid and solid cell nests with necrosis in the chronic inflammatory liver tissue (x100). The Ki-67 labeling index was about 30-40\% (B). C-R indicating the immunohistochemical stainings of CK7, EMA, VILLIN, Hepatocyte, Glypican-3, Arginasc1, AFP, CK19, CK20, CDX2, TTF-1, NapsinA, PAX8, ER, PR, and GATA3, respectively $(x 100)$.

\section{Supplementary Files}


This is a list of supplementary files associated with this preprint. Click to download.

- Additionalfile1.Flowcytologyofbonemarrow.pdf

- Additionalfile3.FigureS2.tif

- Additionalfile2.Figures1.tif 